BMC

Genomics

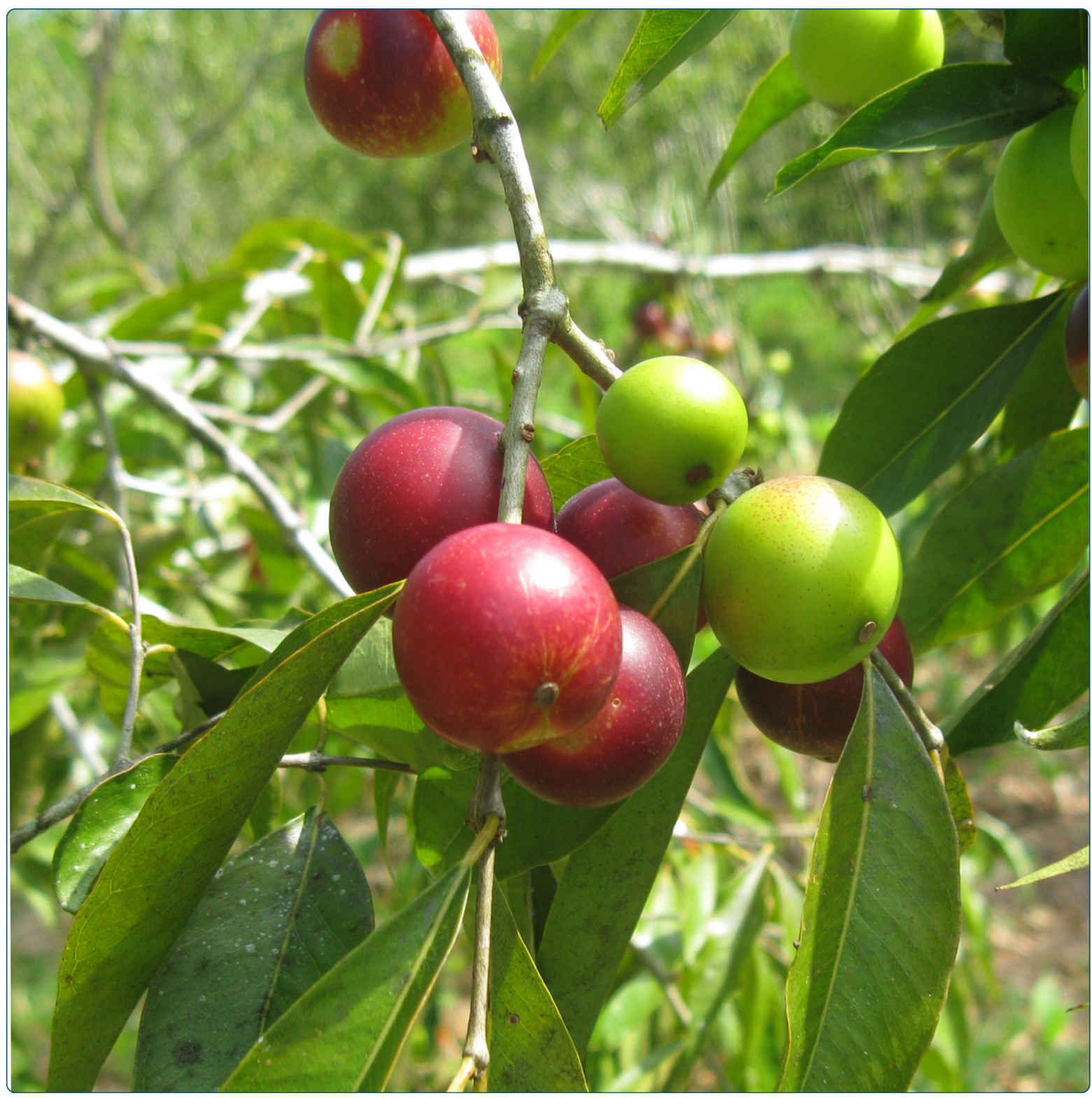

De novo assembly and functional annotation of Myrciaria dubia fruit transcriptome reveals multiple metabolic pathways for L-ascorbic acid biosynthesis

Castro et al.

C Biomed Central 


\title{
De novo assembly and functional annotation of Myrciaria dubia fruit transcriptome reveals multiple metabolic pathways for L-ascorbic acid biosynthesis
}

\author{
Juan C. Castro ${ }^{1,2^{*}}$, J. Dylan Maddox ${ }^{3}$, Marianela Cobos ${ }^{4}$, David Requena ${ }^{5,6}$, Mirko Zimic ${ }^{5,6}$, Aureliano Bombarely ${ }^{7}$,
} Sixto A. Imán ${ }^{8}$, Luis A. Cerdeira ${ }^{1}$ and Andersson E. Medina ${ }^{1}$

\begin{abstract}
Background: Myrciaria dubia is an Amazonian fruit shrub that produces numerous bioactive phytochemicals, but is best known by its high L-ascorbic acid (AsA) content in fruits. Pronounced variation in AsA content has been observed both within and among individuals, but the genetic factors responsible for this variation are largely unknown. The goals of this research, therefore, were to assemble, characterize, and annotate the fruit transcriptome of $M$. dubia in order to reconstruct metabolic pathways and determine if multiple pathways contribute to AsA biosynthesis.

Results: In total 24,551,882 high-quality sequence reads were de novo assembled into 70,048 unigenes (mean length $=1150 \mathrm{bp}, \mathrm{N} 50=1775 \mathrm{bp}$ ). Assembled sequences were annotated using BLASTX against public databases such as TAIR, GR-protein, FB, MGI, RGD, ZFIN, SGN, WB, TIGR_CMR, and JCVI-CMR with $75.2 \%$ of unigenes having annotations. Of the three core GO annotation categories, biological processes comprised $53.6 \%$ of the total assigned annotations, whereas cellular components and molecular functions comprised 23.3 and $23.1 \%$, respectively. Based on the KEGG pathway assignment of the functionally annotated transcripts, five metabolic pathways for AsA biosynthesis were identified: animal-like pathway, myo-inositol pathway, L-gulose pathway, D-mannose/L-galactose pathway, and uronic acid pathway. All transcripts coding enzymes involved in the ascorbate-glutathione cycle were also identified. Finally, we used the assembly to identified 6314 genic microsatellites and 23,481 high quality SNPs.

Conclusions: This study describes the first next-generation sequencing effort and transcriptome annotation of a non-model Amazonian plant that is relevant for AsA production and other bioactive phytochemicals. Genes encoding key enzymes were successfully identified and metabolic pathways involved in biosynthesis of AsA, anthocyanins, and other metabolic pathways have been reconstructed. The identification of these genes and pathways is in agreement with the empirically observed capability of $M$. dubia to synthesize and accumulate AsA and other important molecules, and adds to our current knowledge of the molecular biology and biochemistry of their production in plants. By providing insights into the mechanisms underpinning these metabolic processes, these results can be used to direct efforts to genetically manipulate this organism in order to enhance the production of these bioactive phytochemicals. The accumulation of AsA precursor and discovery of genes associated with their biosynthesis and metabolism in (Continued on next page)
\end{abstract}

\footnotetext{
*Correspondence: juanccgomez@yahoo.es

'Unidad Especializada de Biotecnología, Centro de Investigaciones de

Recursos Naturales de la Amazonía (CIRNA), Universidad Nacional de la

Amazonía Peruana (UNAP), Pasaje Los Paujiles S/N, San Juan Bautista, lquitos,

Perú

${ }^{2}$ Círculo de Investigación en Plantas con Efecto en Salud (FONDECYT No

010-2014), Lima, Perú

Full list of author information is available at the end of the article
}

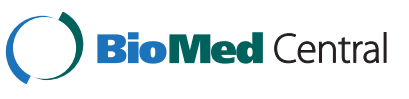

(c) 2015 Castro et al. Open Access This article is distributed under the terms of the Creative Commons Attribution 4.0 International License (http://creativecommons.org/licenses/by/4.0/), which permits unrestricted use, distribution, and reproduction in any medium, provided you give appropriate credit to the original author(s) and the source, provide a link to the Creative Commons license, and indicate if changes were made. The Creative Commons Public Domain Dedication waiver (http://creativecommons.org/publicdomain/zero/1.0/) applies to the data made available in this article, unless otherwise stated. 
(Continued from previous page)

M. dubia is intriguing and worthy of further investigation. The sequences and pathways produced here present the genetic framework required for further studies. Quantitative transcriptomics in concert with studies of the genome, proteome, and metabolome under conditions that stimulate production and accumulation of AsA and their precursors are needed to provide a more comprehensive view of how these pathways for AsA metabolism are regulated and linked in this species.

Keywords: Camu-camu, Metabolic pathway reconstruction, Next-generation sequencing, Plant vitamin C metabolism

\section{Background}

Myrciaria dubia (Kunth) McVaugh "camu-camu" is an diploid Amazonian plant species with $2 n=22$ chromosomes [1] that produces numerous bioactive phytochemicals [2-6], but is best known by its high Vitamin C (L-ascorbic acid) content in fruits [7], which can contain as much as $2 \mathrm{~g}$ of L-ascorbic acid (AsA) per $100 \mathrm{~g}$ of fruit pulp [8], which is equivalent to 50 times the AsA content of orange juice [9]. Pronounced variation in AsA content among different tissue types in the same individual and among individuals has been observed [10], but the genetic factors responsible for AsA content variation in this species are largely unknown.

Results from our research group have demonstrated that M. dubia possesses the capability for AsA biosynthesis in several tissues (unpublished data), and that the large variation of this bioactive molecule in the leaves and fruit pulp and peel is likely due, in part, to differential gene expression and enzyme activities in the D-mannose/L-galactose pathway [11]. In other plant species, radiolabelling, mutant analysis, and transgenic manipulation have provided evidence for the occurrence of multiple metabolic pathways of AsA biosynthesis [12, 13]. It is therefore reasonable to hypothesize that AsA pool size in M. dubia is also the result of multiple metabolic pathways and that their identification and understanding may ultimately explain the large variation observed in AsA content.

Recent advances in high-throughput next-generation sequencing and bioinformatics tools have been used successfully to reveal the transcriptome and identify metabolic pathways in several plant species [14-18]. In this study, we present the sequencing, assembly, and annotation of the fruit transcriptome of $M$. dubia in order to reconstruct metabolic pathways and identify those associated with AsA biosynthesis.

\section{Results}

Illumina paired end sequencing and de novo assembly A total of 25,787,070 raw sequencing reads of $100 \mathrm{bp}$ were generated from a $200 \mathrm{bp}$ insert library. After raw reads were filtered and cleaned, 24,551,882 (95.2 \%) high-quality reads were used to assemble the fruit transcriptome of $M$. dubia. A total of 70,048 unigenes were generated in the meta-assembly with a length between 200 and $8059 \mathrm{bp}$, mean length of $1150 \mathrm{bp}$, and a N50 of 1775 bp (Fig. 1). The Illumina paired-end reads have been submitted to the Short Read Archive [SRA: SRR1630824].

Functional annotation, and metabolic pathway assignments All unigenes were included in the annotation process. This process included best BLASTX match selection, Gene Ontology ID assignment, enzyme code assignments and InterPro domains calculation. BLASTX comparison with the NCBI nonredundant (nr) database revealed 52,707 (75.2 \%) unigenes with annotations (Fig. 2). A significant amount of mapping data (93.0\% of unigenes with mapping information) was derived from UniProtKB database followed by TAIR and GR_protein. Additional databases (i.e., FB, MGI, RGD, ZFIN, SGN, WB, TIGR_CMR, and JCVI-CMR) were searched but did not contribute to the mapping process. The top five species that contributed the greatest number of gene annotations from BLASTx were Vitis vinifera, Theobroma cacao, Populus trichocarpa, Prunus persica, and Ricinus communis (Fig. 3).

Of the three core GO annotation categories, biological processes (BP) comprised $53.6 \%$ of the total assigned annotations, whereas cellular components (CC) and molecular functions (MF) comprised $23.3 \%$ and $23.1 \%$, respectively. The GO terms with the largest number of

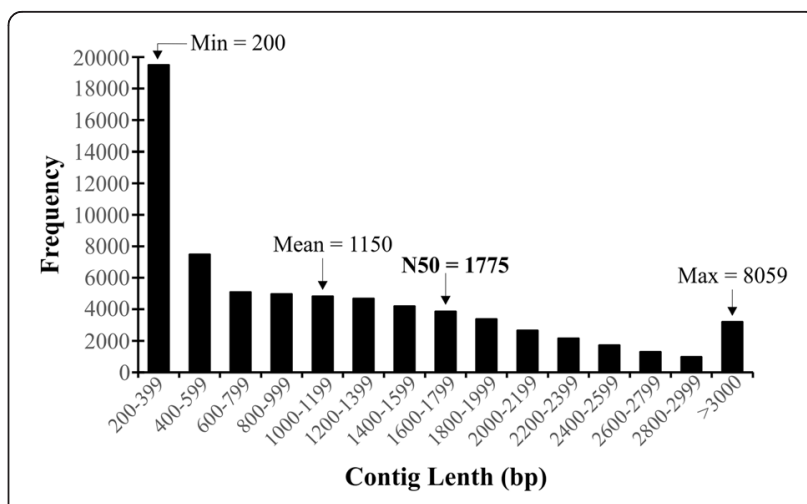

Fig. 1 Distribution of unigene lengths after de novo transcriptome assembly of fruits from M. dubia 


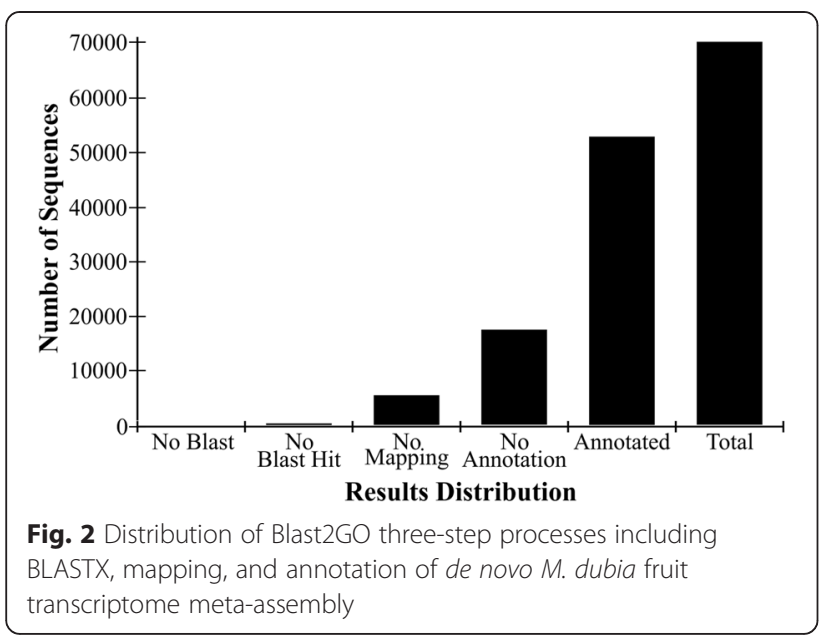

assigned sequences in the BP category were ATP binding (7,741; $3.5 \%)$, zinc ion binding $(4,467 ; 2.0 \%)$, DNA binding (3682; $1.7 \%$ ), and sequence-specific DNA binding transcription factor activity $(2,986 ; 1.3 \%$ ) (Fig. 4). For $\mathrm{CC}$ the terms with the most sequences were nucleus $(10,891 ; 11.3)$, plasma membrane $(9,153 ; 9.5 \%)$, mitochondrion (6,562; $6.8 \%)$, and cytosol (5,545; $5.8 \%)$. In the MF category the terms with the most sequences were oxidation-reduction process $(4,445 ; 4.7 \%)$, serine family amino acid metabolic process $(3,309 ; 3.5 \%)$, regulation of transcription, DNA-dependent (3,293; $3.5 \%)$, and protein phosphorylation $(2,336 ; 2.4 \%)$. In total, KEGG maps for more than 160 metabolic pathways were generated. The full pathway list and the KEGG maps are available as Additional file 1: Table S1 and Additional file 2: Figure S1, respectively.

\section{L-ascorbic acid biosynthesis and recycling}

Although the metabolic pathways for AsA biosynthesis and recycling are known for several plant species, the

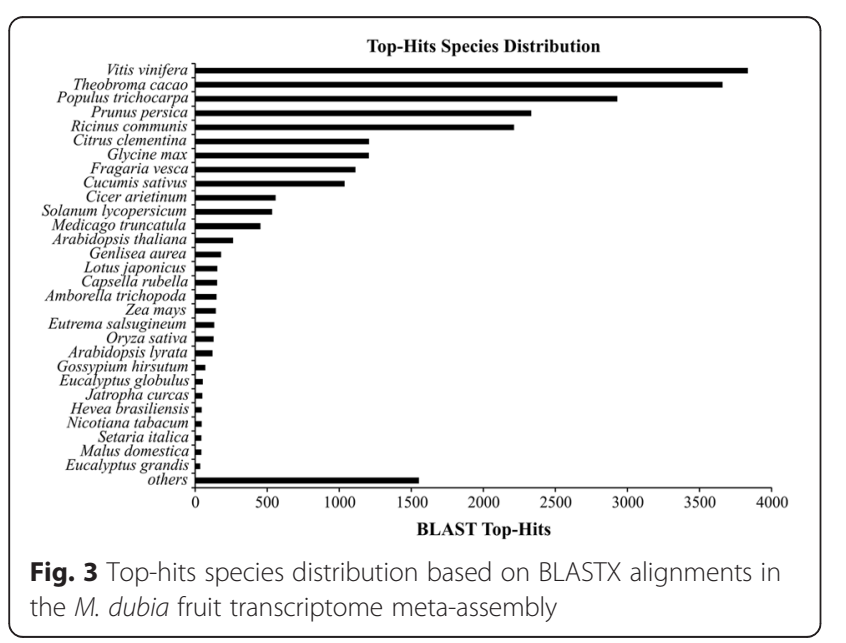

existing knowledge of these pathways and enzymes involved in M. dubia are limited. Based on the KEGG pathway assignment (map00010, map00051, map00053, map00500, map00520, and map00562) of the functionally annotated sequences and local blast search of the de novo meta-assembly transcriptome, transcripts coding for the D-mannose/L-galactose pathway were found. This pathway involves the generation of AsA from Dmannose-1-phosphate (Fig. 5). GDP-D-mannose synthesis from D-mannose-1-phosphate and GTP is catalyzed by GDP-D-mannose pyrophosphorylase (E.C. 2.7.7.13), GDP-D-mannose is converted to GDP-L-galactose by a reversible double epimerization, catalyzed by GDPmannose-3',5'-epimerase (E.C. 5.1.3.18), then GDP-Lgalactose is broken down by GDP-L-galactose:hexose1-phosphate guanyltransferase (E.C. 2.7.7.69) to Lgalactose-1-phosphate, which is subsequently hydrolyzed to L-galactose and inorganic phosphate by L-galactose-1phosphate phosphatase (E.C. 3.1.3.25). L-galactose is then oxidized to L-galactono-1,4-lactone by the NADdependent L-galactose dehydrogenase (E.C. 1.1.1.316), finally L-galactono-1,4-lactone is oxidized to AsA by Lgalactono-1,4-lactone dehydrogenase (E.C. 1.3.2.3).

Four additional AsA biosynthetic pathways were also identified. The first is the animal-like pathway. In this pathway D-glucuronic acid is generated from $\mathrm{D}$ glucose via the intermediates: D-glucose-1-phosphate, UDP-D-glucose, UDP-D-glucuronic acid, and Dglucuronic acid-1-phosphate. D-glucuronic acid is then converted to L-gulonic acid by glucuronate reductase (E.C. 1.1.1.2), which is converted to L-gulono1,4-lactone, from this compound AsA is generated by Lgulono-1,4-lactone oxidase/dehydrogenase (E.C. 1.1.3.8). The second alternative pathway uses myo-inositol as a precursor of AsA. In this pathway, D-glucuronic acid, an intermediate of the animal-like pathway, can be generated from myo-inositol by inositol oxygenase (E.C. 1.13.99.1). The third is the L-gulose pathway. In this putative pathway, the first metabolic intermediary (GDP-L-gulose) is generated from GDP-D-mannose by action of GDPmannose-3',5'-epimerase (E.C. 5.1.3.18), subsequently GDP-L-gulose is transformed to L-gulono-1,4-lactone throughput four sequential biochemical reactions. Finally, the fourth is the uronic acid pathway. In this pathway pectin-derived D-galacturonic acid is metabolized to AsA by an inversion pathway. The enzyme $\mathrm{D}$-galacturonic acid reductase (E.C. 1.1.1.365) reduces the compound Dgalacturonic acid to L-galactonic acid, which in turn is spontaneously converted to L-galactono-1,4-lactone. This compound is the substrate of the L-galactono-1,4-lactone dehydrogenase enzyme (E.C. 1.3.2.3).

We also identified all transcripts coding enzymes involved in the recycling pathway (i.e., ascorbate-gluthatione cycle). When AsA is oxidized to monodehydroascorbate 


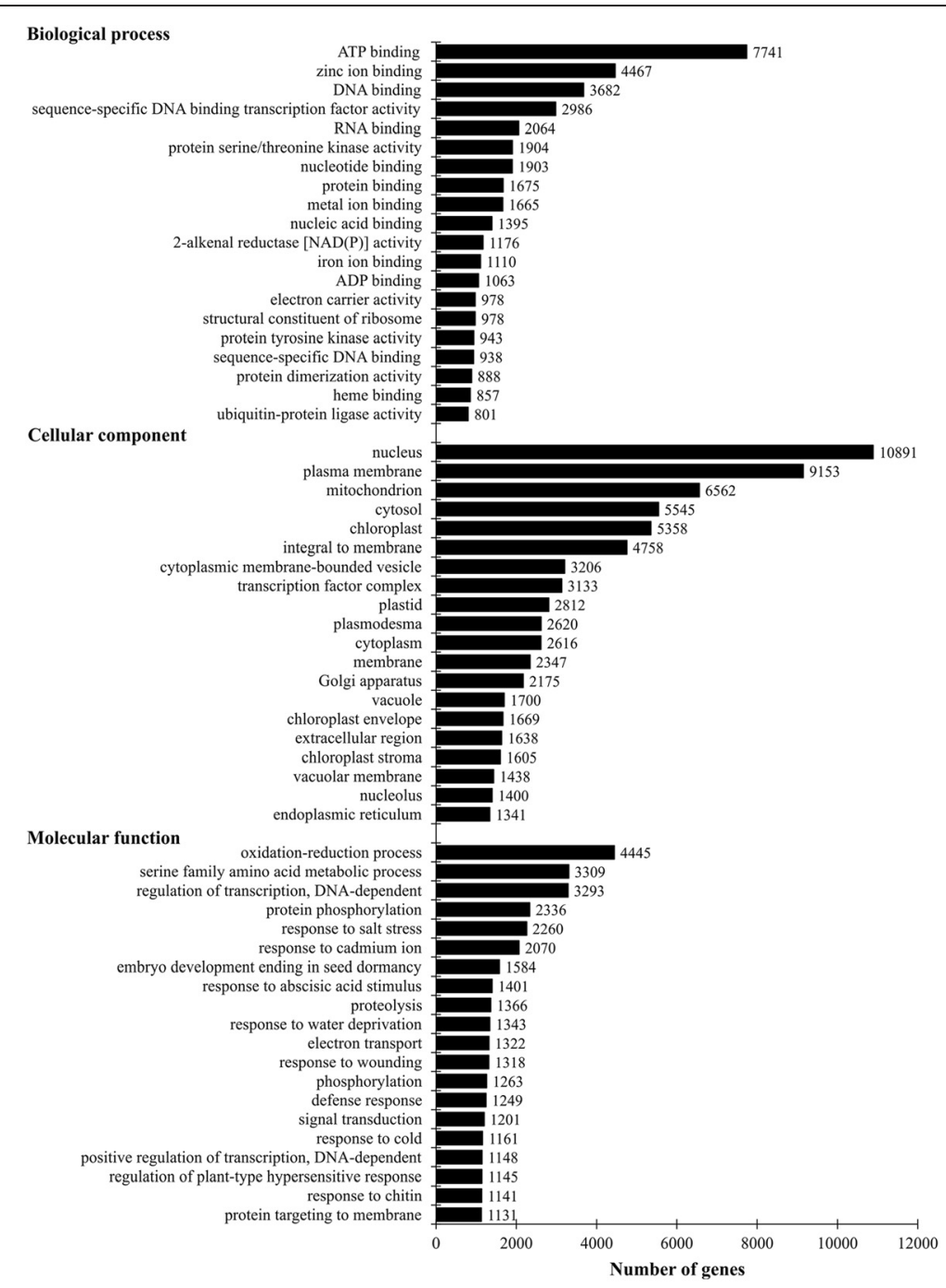

Fig. 4 Gene Ontology classifications of assembled sequences. Numbers indicate the number of sequences associated with the particulate GO term

by ascorbate peroxidase (E.C. 1.11.1.11), it can be reduced to AsA by monodehydroascorbate reductase (E.C. 1.6.5.4) or it can disproportionate non-enzymatically to AsA and dehydroascorbate (DHA). DHA can also be reduced to AsA by dehydroascorbate reductase (E.C. 1.8.5.1), using glutathione as the reductant (GSH) that is then converted to oxidized glutathione (GSSG). Finally, this compound is reduced by glutathione reductase (E.C. 1.8.1.7) using $\mathrm{NADPH}$ as the reductant.

\section{Discovery of molecular markers}

All unigenes $(70,048)$ of the meta-assembly were used to mine potential genic simple sequence repeats (genicSSR) or microsatellites that were defined as di- to hexanucleotide motifs with a minimum of five repetitions. A total of 30 motifs with simple sequence repeats were identified in 6,314 (9.0\%) unigenes, but 287 genic-SSRs were included in unigenes without a match in the $\mathrm{nr}$ database (Additional file 3: Table S2). The di-nucleotide repeat AG/TC was the most abundant type (91.0\%), followed by other di- $(4.4 \%)$ and tri-nucleotide repeats (3.9\%; Fig. 6). The tetra-, penta-, and hexa-nucleotide repeats together exhibited the lowest frequency $(0.7 \%)$. Using Primer 3 Software we were able to design primers for 3,240 unigenes containing SSRs with product size ranging from 100 to $450 \mathrm{bp}$ (Additional file 4: Table S3).

A total of 73,889 putative SNPs were also discovered, although only 23,481 met the selection criteria for robustness. The majority of these SNPs were bi-allelic $(23,464)$ and only 17 were tri-allelic. These SNPs were found in 5,587 unigenes of which 5,226 (93.5 \%) could be annotated with a GO term (Additional file 5: Table S4). The transition substitutions ( $33.5 \% \mathrm{G} \leftrightarrow \mathrm{A}$, and 33.6 $\% \mathrm{~T} \leftrightarrow \mathrm{C}$; totalling $67 \%)$ were high compared to 


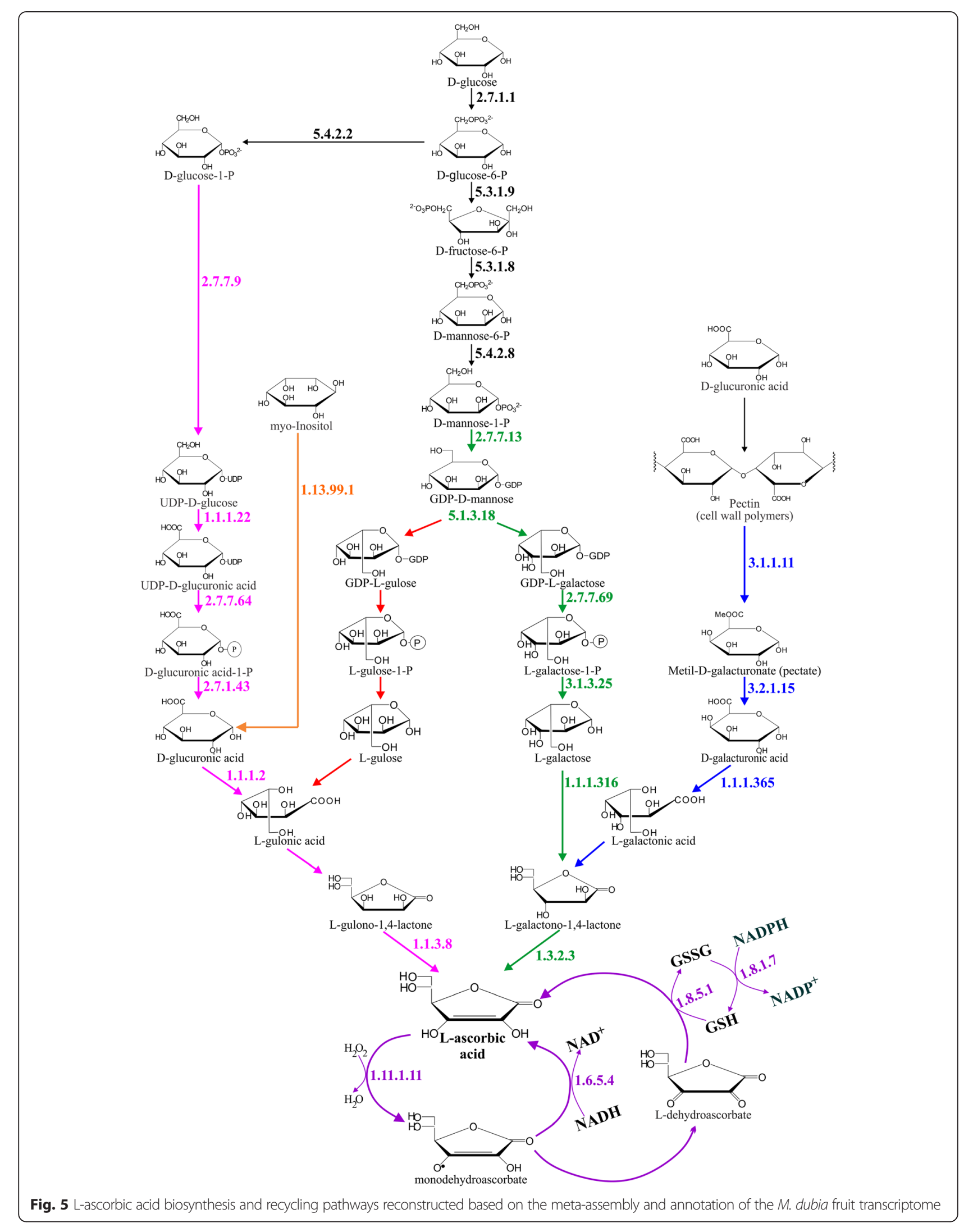




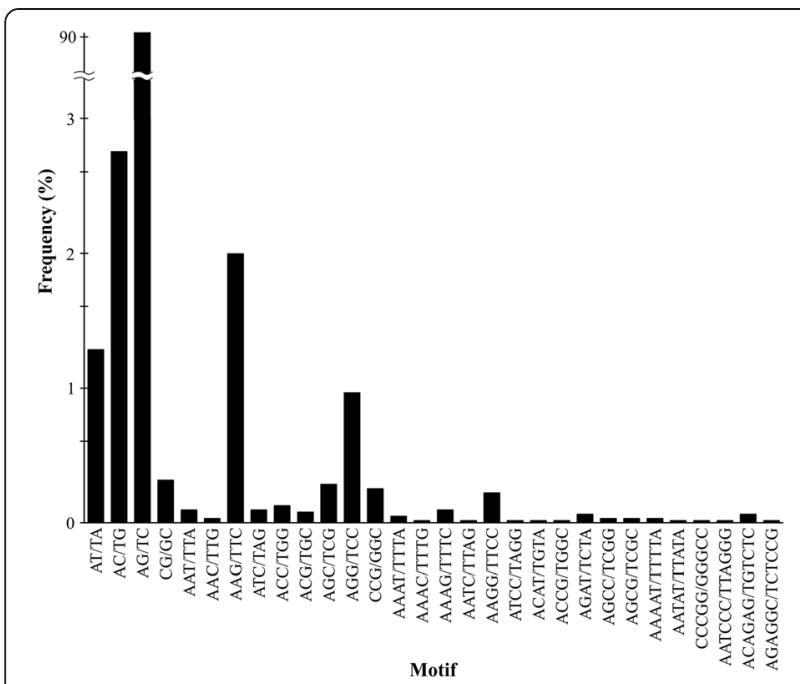

Fig. 6 Frequency distribution of simple sequence repeats based on motif types identified in the M. dubia fruit transcriptome meta-assembly

transversions $(6.7 \% \mathrm{C} \leftrightarrow \mathrm{A}, 9.9 \% \mathrm{G} \leftrightarrow \mathrm{C}, 7.5 \% \mathrm{~T} \leftrightarrow \mathrm{A}$, and $8.9 \% \mathrm{~T} \leftrightarrow \mathrm{G}$; totalling $33 \%$ ) with an observed transition over transversion ratio of approximately 2.0.

Several of the genes involved in AsA metabolism proved to be polymorphic as evidenced by SNP discovery. For example, the D-mannose/L-galactose pathway mannose-1-phosphate guanylyltransferase (E.C. 2.7.7.13) contained >20 SNPs, GDP-mannose-3',5'-epimerase (E.C. 5.1.3.18) had 13 SNPs, whereas L-galactono-1,4lactone dehydrogenase (E.C. 1.3.2.3) only had 5 SNPs. The animal-like pathway UTP:glucose-1-phosphate uridylyltransferase (E.C. 2.7.7.9) contained 7 SNPs. In the uronic acid pathway pectin esterase (E.C. 3.1.1.11) and galacturan-1,4-alpha-galacturonidase (E.C. 3.2.1.15) showed more than 20 and 14 SNPs, respectively. Finally, in the ascorbate-glutathione pathway the unigenes monodehydroascorbate reductase (E.C. 1.6.5.4) and glutathione reductase (E.C. 1.8.1.7) contained 2 and 3 SNPs, respectively (Additional file 6: Table S5).

\section{Discussion}

\section{Illumina paired end sequencing and de novo assembly}

Fruit transcriptome sequencing of $M$. dubia with Illumina paired end sequencing technology and de novo assembly with the meta-assembly bioinformatics strategy were able to produce more than 24 million high-quality reads, and $\sim 70,000$ assembled unigenes with high N50 value (Fig. 1). Similar strategies have been widely utilized for successful de novo transcriptome sequencing and assembly of fruits in other plant species such as Ananas comosus [19], Capsicum annuum [20], Litchi chinensis [17], Mangifera indica [21], Momordica cochinchinensis [22], Pyrus bretschneideri [23], and Vaccinium spp. [24].
Additionally, analogous approaches were effectively used for sequencing and de novo assembly of transcriptome in various tissues of several non-model plant species without a reference genome [25-35]. The novel assembly methods [36-39] have made short read assembly to be a cost-effective and reliable tool for gene discovery and molecular markers development in non-model plant species.

\section{Functional annotation and metabolic pathway assignments} In the present study we annotated $75.2 \%$ of the assembled transcriptome, leaving 17,341 unigenes unidentified. Similar results with a large number of unidentified sequences have been reported for other non-model organisms [17, 19-24, 26]. These unidentified sequences are likely to correspond to non-coding RNAs; short sequences lacking informative domains for conclusive annotation; or novel and/or specific genes of $M$. dubia that have not been previously characterized or coding orphan enzymes (i.e., unannotated gene sequences). The latter are all sequence-lacking enzymatic activities described in the literature and often catalogued in the EC database [40]. According to Sorokina et al. [41], 22.4 \% of enzymatic activities from 5,096 ECs were orphans, and a large proportion of pathways (87\% in KEGG and $36 \%$ in MetaCyc) contain at least one orphan activity. Of the pathways containing a mix of orphan and non-orphan activities in KEGG and MetaCyc, an average of $26.0 \%$ and $39.5 \%$ of the reactions per pathway corresponds to orphan enzymes, respectively. Consequently, most metabolic pathways are still not entirely resolved at the gene level, which restricts in silico reconstructions of metabolic pathways.

Two additional problems that create challenges for automated reconstructions of metabolic pathways are the number of misannotations in large public databases and the variation in metabolic pathways. First, Schnoes et al. [42] investigating the prevalence of annotation error in primary and secondary large public protein databases commonly used today, found that the manually curated database Swiss-Prot shows the lowest annotation error levels. The other two protein sequence databases (GenBank NR and TrEMBL) and the protein sequences in the KEGG pathways database exhibit similar and surprisingly high levels of misannotation that average $25 \%$ in the enolase superfamily to over $60 \%$ in the HAD superfamily. Second, the availability of sequenced genomes has revealed the diversity of biochemical solutions to similar chemical problems, because the pathway enzymes first discovered in model organisms are often not universally conserved [43]. For example, the tetrahydrofolate biosynthesis pathway and enzymes are not universal and alternate solutions are found for most steps, making this pathway and others like it a challenge for automatic annotation in many genomes [43]. 
Due to these limitations several metabolic pathways reconstructed from the annotated unigenes of $M$. dubia show gaps or missing genes. Consequently, comparative genomics, enzymatic, metabolomic, and structural analyses will be required to fill these pathway gaps [40, 44-46]. Despite such limitations, it was possible to completely reconstruct several KEGG pathways with the M. dubia transcriptome. The well represented pathways discovered in this study included L-ascorbic acid biosynthesis and recycling, phenylpropanoid biosynthesis, flavonoid biosynthesis, anthocyanin biosynthesis, pentose phosphate pathway, glutathione metabolism, plant pathogen interaction, biosynthesis of plant hormones, aminoacids biosynthesis and degradation, and circadian rhythm (Additional file 1: Table S1 and Additional file 2: Figure S1). In conclusion, while transcriptomic analysis is not a substitute for detailed gene and pathway studies, it does provide a broad overview of the important metabolic processes from which to efficiently build hypotheses that can guide future detailed studies on improving our understanding of L-ascorbic acid metabolism and the accumulation of other bioactive phytochemicals in this plant species.

\section{L-ascorbic acid biosynthesis and recycling}

Plants can possess a total of five metabolic pathways for AsA biosynthesis. These metabolic pathways are the animal-like pathway [47], the myo-inositol pathway [48], the L-gulose pathway [49], the D-mannose/L-galactose pathway [11], and the uronic acid pathway [12]. All these pathways were identified in the fruit transcriptome of $M$. dubia (Fig. 5) and have also been documented in other plant species. For example, analysis of the Citrus sinensis fruit transcriptome indicated that genes from four of the five biosynthetic pathways (all but the animal-like pathway) are expressed [50], whereas expressed sequence tags from fruits and other tissues of four Actinidia species (A. arguta, A. chinensis, A. deliciosa, and A. eriantha) indicated that myo-inositol, D-mannose/L-galactose, and uronic acid are active [51]. In contrast, the analysis of fruit transcriptomes of Ziziphus jujuba, Myrica rubra, and Ananas comosus were only able to identify the D-mannose/L-galactose pathway as active [19, 52, 53]. From an evolutionary perspective, however, it is possible that many or even most of these metabolic pathways for AsA biosynthesis are conserved in plants, because AsA is one of the most abundant low molecular weight antioxidant of plants that plays an essential role in the detoxification of reactive oxygen species. In addition, AsA is important in plant development, hormone and light signaling, cell cycle, death, and cell expansion, pathogen responses, and as a cofactor for several key enzymes $[13,47,54,55]$. Consequently, the differential activation of one or more, but not all five, metabolic pathways from the above examples via gene expression depends on several factors (e.g., organ/tissue type, development stage, physiological condition, environmental factors) and does not necessarily indicate their absence.

The L-gulose pathway is derived from the D-mannose/ L-galactose pathway by action of the GDP-mannose$3^{\prime}, 5^{\prime}$-epimerase (E.C. 5.1.3.18) and evidence exists that it is active in plant cells, because both L-gulose and Lgulono-1,4-lactone serve as precursors of L-ascorbic acid biosynthesis [49], but have limited molecular and biochemical studies. To date, genic sequences coding enzymes catalysing four consecutive biochemical reactions are unknown: GDP-L-gulose $\rightarrow$ L-gulose-1-phosphate $\rightarrow$ L-gulose $\rightarrow$ L-gulonic acid $\rightarrow$ L-gulono-1,4-lactone (or L-gulose $\rightarrow$ L-gulono-1,4-lactone) $\rightarrow$ L-ascorbic acid. Except for L-gulono-1,4-lactone dehydrogenase, enzyme activities for these biochemical reactions also were not tested. Enzymatic activity of L-gulono-1,4-lactone dehydrogenase has been observed in cytosolic and mitochondrial fractions of the leaves and fruit pulp and peel of M. dubia [56] and tubers of Solanum tuberosum [49]. In addition, the genome of Arabidopsis thaliana contains genes (i.e., At1g 32300, At2g 46740, At2g 46750, At2g 46760, At5g11540, and At5g 56490) that are closely related with the rat L-gulono-1,4-lactone oxidase. Some of these genes could be coding enzymes responsible for the conversion of L-gulono-1,4-lactone to AsA [49]. Also, one putative unigene, probably coding for this enzyme, was identified in our assembled transcriptome (E.C. 1.1.3.8).

Some of the biochemical reactions of the L-gulose pathway, however, can likely be catalysed from promiscuous enzymes, which is an inherent property of many enzymes catalysing analogous biochemical reactions [57]. Indeed, some enzymes of the D-mannose/ L-galactose pathway catalysing similar reactions of the L-gulose pathway have shown promiscuity. For example, the enzyme GDP-L-galactose:hexose 1phosphate guanyltransferase (E.C. 2.7.7.69) has a low $\mathrm{Km}$ value $(10 \mu \mathrm{M}$ and $4.4 \mu \mathrm{M})$, a high turnover rate kcat $\left(64 \mathrm{~s}^{-1}\right.$ and $\left.23 \mathrm{~s}^{-1}\right)$, and a similar specificity constant $\mathrm{kcat} / \mathrm{Km}\left(6.3 \times 10^{6} \mathrm{~s}^{-1} \mathrm{M}^{-1}\right.$ and $\left.5.7 \times 10^{6} \mathrm{~s}^{-1} \mathrm{M}^{-1}\right)$ with the GDP-L-galactose and GDP-D-glucose substrates, respectively [58]. Furthermore, the enzyme L-galactose dehydrogenase catalyses the oxidative reduction of both L-galactose and L-gulose substrates in Spinacia oleracea [59]. Consequently, it is necessary to conduct additional research to further our understanding of these genes, enzymes and the contribution of these metabolic pathways to AsA biosynthesis and accumulation in fruits, other organs and tissues of M. dubia. 
Based on the KEGG pathway assignments, we identified transcripts coding for all enzymes of the ascorbateglutathione or "Foyer-Halliwell-Asada" pathway (Fig. 5). The enzymes of this metabolic pathway have been localized in several compartments of the plant cells, such as the cytosol, mitochondria, peroxisomes, and chloroplast $[60,61]$. This distribution of the ascorbate-glutathione pathway components is attributable to its vital role, since this pathway is recognized to be a key player in $\mathrm{H}_{2} \mathrm{O}_{2}$ metabolism and AsA recycling [54]. AsA recycling requires a continuous supply of GSH and NADPH. The pathways supplying these reductant molecules lie outside of the AsA biosynthetic machinery. The key suppliers of GSH are by de novo biosynthesis in two ATPdependent reactions catalyzed by $\gamma$-glutamylcysteine synthetase and glutathione synthetase [62]. The second biochemical process is catalyzed by glutathione reductase (E.C. 1.8.1.7), which uses NADPH to reduce GSSG to GSH [54]. Moreover, there are various sources of the essential reductant NADPH. The first and principal source is the oxidative pentose phosphate pathway [63]. The second significant source includes L-malate:NADP oxidoreductase (E.C. 1.1.1.40) that catalyzes the oxidative decarboxylation of L-malate to yield pyruvate, $\mathrm{CO}_{2}$ and NADPH in the presence of a bivalent cation [64]. Finally, NADPH is generated in photosynthetic cells (i.e. immature fruit peel of $M$. dubia) primarily from the light reactions of photosynthesis [65]. Therefore, genetic manipulations that increase the availability of GSH and $\mathrm{NADPH}$ for AsA recycling, through up-regulation/overexpression of related genes identified here, could be promising approaches to increase the yield of AsA in $M$. dubia and other plant species.

\section{Discovery of molecular markers}

It is well-known that genic-SSR markers have numerous applications, such as functional genomics, association mapping, diversity analysis, genome mapping, transferability and comparative mapping, marker assisted selection breeding, and other applications [66]. Nevertheless, only eight genic-SSR markers have been developed for M. dubia until now $[67,68]$, limiting the applications previously mentioned. However, with this research mining the assembly fruit transcriptome of M. dubia it was possible to identify a large number of unigenes containing SSR (primers were designed for 3,240 unigenes) motifs that would be appropriates for developing a comprehensive set of genic-SSR markers that will need experimental validation. In conclusion, the genic-SSR markers identified in the assembly transcriptome database represent a significant addition to the limited set of markers available in M. dubia and it will be feasible to conduct marker assisted gene mapping for important agronomical traits (e.g., L-ascorbic acid and anthocyanin accumulation, fruit size) or biological processes (e.g., seed germination, growth and development, disease resistance, etc.).

Our results regarding genic-SSR markers are largely similar to other plant studies, but differences do exist. First, the percentage of unigenes containing SSRs $(9.0 \%$ in $M$. dubia) is comparable to reports for this species from Brazil with $10.9 \%$ [67] as well as for Ipomoea batatas with $7.3 \%$ [32], Cajanus cajan with $7.7 \%$ [69], Capsicum anuum with 7.7 \% [15], and Sesamum indicum with $8.9 \%$ [28]. Differences, however, existed when compared to Apium graveolens with $6.2 \%$ [70] and the monocot Phoenix dactylifera with 16.0 \% [71]. Second, regarding the distribution of the perfect repeat motif types, tri-nucleotide repeats have generally been observed to have the highest frequency in cereals and other plant species [71-73]. However, here, as in a previous study on M. dubia [67] and other plant species [14, 28, $69,70,74]$, the most abundant repeat motif type was dinucleotide repeats, followed by tri-nucleotide repeats. Of the thirty motifs, (AG/TC)n showed the highest frequency $(91.0 \%)$, which is in agreement with other plant species $[14,28,32,71,74]$. As in monocot [74] and other dicot plants $[28,32,75]$ the (AAG/TTC)n motif in $M$. dubia was the most abundant of the tri-nucleotide repeat motifs. This triplet codes for lysine, which is commonly found in the exons of plants [75]. This finding is consistent with Katti et al. [76] who showed that expansions of codon repeats corresponding to small hydrophilic amino acids are tolerated more, while strong selection pressures probably eliminate codon repeats encoding for hydrophobic and basic amino acids.

In addition, in our dataset some unigenes containing genic-SSR were lacking functional annotations. These unidentified unigenes probably correspond to untranslated (UTR) regions. Several researches showed that SSR frequency is high in the $5^{\prime}$ UTR regions of plant transcripts [77-80], suggesting that SSRs located in this genic region can potentially act as factors in regulating gene expression in the transcriptional or translational levels $[78,81]$. Consequently, these insights are likely to play a significant role in selecting SSRs loci to be used in molecular breeding programs of $M$. dubia.

Sequencing a pool of cDNA using next-generation sequencing technologies and appropriate mining software allows for the rapid and inexpensive SNP discovery within genes in non-model plants without a reference genome. Our transcriptome dataset contained a large number of high quality SNPs $(>23,000)$ and marks the highest number of SNP markers discovered to date from M. dubia using transcriptome sequencing. While the majority of SNPs were bi-allelic (>99.9 \%), an insignificant fraction showed tri-allelic $(0.072 \%)$ polymorphisms. These results are in agreement with the diploid nature 
of the M. dubia genome [1]. Similar low levels of triallelic SNPs also were reported in other plant species such as Brassica napus with 0.029-0.06 \% [82, 83] and Manihot esculenta with $0.52 \%$ [84], whereas tri-allelic SNPs were not detected in Sesamum indicum [85] and Hevea brasiliensis [86]. Nevertheless, the switchgrass Panicum virgatum possesses a substancial number of tri-allelic SNPs (15\%), which is consistent with the polyploid condition of the genome of this species [87]. Although in principle, at each position of a sequence any of the four nucleotide bases can be present, however, SNPs are frequently biallelic. One possible explanation is the low frequency of single nucleotide substitutions (5.0$\left.30.0 \times 10^{-9}\right)$ at the nuclear genes of plants [88]. Consequently, the probability of two or three independent mutations occurring at a single position is very low. Another important cause for the prevalence of bi-allelic SNP is attributable to a clear bias in the mutation mechanism that results in a prevalence of transitions over transversions exchanges (67\% vs $33 \%$ in our data set). One probable explanation for this is the high frequency of spontaneous deamination of 5-methyl cytosine to thymidine in the $\mathrm{CpG}$ dinucleotides [89].

Although SNPs are less polymorphic than SSR markers, they easily compensate for this drawback by being abundant and amenable to high- and ultrahigh-throughput automation [90]. Consequently, this large collection of SNP markers could facilitate genetic applications in M. dubia such as genetic diversity and characterization, linkage mapping, high-density quantitative trait locus analysis, association studies, map-based cloning, marker-assisted plant breeding, and functional genomics.

\section{Conclusions}

This study describes the first next-generation sequencing effort and transcriptome annotation of a non-model Amazonian plant that is relevant for AsA production and other bioactive phytochemicals. Genes encoding key enzymes were successfully identified and metabolic pathways involved in biosynthesis of AsA, anthocyanins, and other metabolic pathways have been reconstructed. The identification of these genes and pathways is in agreement with the empirically observed capability of $M$. dubia to synthesize and accumulate AsA and other important molecules, and adds to our current knowledge of the molecular biology and biochemistry of their production in plants. By providing insights into the mechanisms underpinning these metabolic processes, these results can be used to direct efforts to genetically manipulate this organism in order to enhance the production of these bioactive phytochemicals.

The accumulation of AsA precursor and discovery of genes associated with their biosynthesis and metabolism in M. dubia is intriguing and worthy of further investigation. The sequences and pathways produced here present the genetic framework required for further studies. Quantitative transcriptomics in concert with studies of the genome, proteome, and metabolome under conditions that stimulate production and accumulation of AsA and their precursors are needed to provide a more comprehensive view of how these pathways for AsA metabolism are regulated and linked in this species.

\section{Methods}

\section{Plant material}

Unripe (60 days after anthesis) and ripe fruits (70 days after anthesis) were randomly collected from 10 different accessions (one plant by accession) from the M. dubia germplasm bank $\left(03^{\circ} 57^{\prime} 17^{\prime \prime} \mathrm{S}, 73^{\circ} 24^{\prime} 55^{\prime \prime} \mathrm{W}\right)$ at the Instituto Nacional de Innovación Agraria of Peru, region Loreto. Established approximately 20 years ago, this germplasm bank consists of 43 representative accessions of genetic variability of $M$. dubia from the eight major river basins of the Loreto Region (Nanay, Itaya, Napo, Ucayali, Putumayo, Curaray, Tigre and Amazonas). Immediately after harvesting, samples were stored at $-80^{\circ} \mathrm{C}$ until further use. A graphical representation of our work flow is provided in Additional file 7: Figure S2.

\section{Total RNA isolation and CDNA synthesis}

Total RNA was isolated from seeds and fruit pulp and peel from each of the 10 plants using the CTAB method, solvent extractions, and DNase treatment as described by Castro et al. [91]. RNA samples were chosen and pooled equally for cDNA library construction and sequencing if the $\mathrm{OD}$ ratio $\mathrm{A}_{260} / \mathrm{A}_{280}>1.9, \mathrm{~A}_{260} / \mathrm{A}_{230}>$ 2.0 , and the samples were not degraded as assessed by formaldehyde denaturing gel electrophoresis [92].

\section{cDNA library construction and sequencing}

Illumina sequencing was performed at Macrogen's sequencing service according to the manufacturer's instructions (Illumina Inc., San Diego, CA, USA). First, mRNA with a poly(A) tail was isolated from $20 \mu \mathrm{g}$ of pooled total RNA using Sera-mag magnetic oligo (dT) beads (Illumina). To avoid priming bias, the purified mRNA was first fragmented into small pieces (100-400 bp) using divalent cations at $94^{\circ} \mathrm{C}$ for 5 minutes. With random hexamer primers (Illumina), the doublestranded cDNA was synthesized using the SuperScript double-stranded cDNA synthesis kit (Invitrogen, CA). The synthesized cDNA was subjected to end-repair and phosphorylation, and then the repaired cDNA fragments were $3^{\prime}$ adenylated with Klenow Exo- $\left(3^{\prime}\right.$ to $5^{\prime}$ exo minus, Illumina). Illumina paired-end adapters were ligated to the ends of these 3 '-adenylated cDNA fragments. To select the proper templates for downstream 
enrichment, products from the ligation reaction were gel ( $2 \%$ agarose) purified and excised. Fifteen cycles of PCR amplification were carried out to enrich the purified cDNA template using PCR primers PE 1.0 and 2.0 (Illumina) with phusion DNA polymerase. Finally, the cDNA library was constructed with a 200 bp insertion fragment. After validation on an Agilent Technologies 2100 Bioanalyzer, the library was sequenced using an Illumina HiSeq $^{\text {ti }} 2000$ (Illumina Inc., San Diego, CA, USA).

\section{Data filtering and de novo assembly}

Prior to assembly raw sequencing reads were filtered and trimmed with Trimmomatic v0.32 [93] using the following steps: (1) leading and trailing bases of low quality or $\mathrm{N}$ bases were removed, (2) the $3^{\prime}$ end was cut and removed if the quality score of a $4 \mathrm{bp}$ wide sliding window dropped below 15, and (3) remaining reads less than 36 bp and singletons were removed.

Cleaned reads were de novo assembled following the multiple k-mer approach of Melicher et al. [94]. Briefly, we used Velvet v1.2.10 [36] and Oases v0.2.08 [37] to produce assembles of k-mer lengths $21,25,29,33$, and 37 . An additional assembly was produced with Trinity v20140717 [38] using the default settings at a k-length of 25 . The transcripts from the 6 assemblies were then pooled and reassembled using CAP3 [39] to produce a meta-assembly.

\section{Functional annotation, and metabolic pathway assignments}

To elucidate the potential functions of gene transcripts we utilized the web tool FastAnnotator [95], which integrates the well-established annotation tools Blast2GO [96], PRIAM [97], and RPS BLAST [98] to assign Gene Ontology (GO) terms, Enzyme Commission numbers (EC numbers), and functional domains to query sequences (cut-off Evalue $\leq 10^{-6}$ ). To determine metabolic pathways, sequences assigned ECs from FastAnnotator were mapped to the Kyoto Encyclopedia of Genes and Genomes (KEGG) metabolic pathway database [99]. To further enrich the pathway annotation and to identify the BRITE functional hierarchies, sequences were also submitted to the KEGG Automatic Annotation Server (KAAS) [100] with the single-directional best hit information method selected.

\section{Discovery of molecular markers}

Unigenes were mined for genic simple sequence repeats (genic-SSR) with MSATCOMMANDER v1.0.8 [101] and primers designed with the integrated Primer 3 Software [102] using the default setting for both programs, except that only perfect repeats (i.e., di-, tri-, tetra-, penta-, hexanucleotides) were selected and mononucleotide repeats and complex SSR types were excluded. Only those genic-SSRs with $\geq 5$ repeats were retained.
SNPs were identified by first mapping the filtered reads to the final meta-assembly using BWA v0.7.10 [103] and then mpileup of SAMtools v1.1 [104] was used to detect SNP sites. Only SNPs with quality scores $>20$ and coverage depth $>20$ were labeled as high quality. The locations of the SNPs in unigenes were predicted with TransDecoder (http://transdecoder.github.io/) and snpEff v3.1 [105] was used to predict the effects of SNPs on genes.

\section{Additional files} Additional file 1: Table S1. KEEG Pathway list in transcriptome of $M$.
dubia. (CSV $6 \mathrm{~kb}$ )

Additional file 2: Figure S1. KEEG Pathway Maps in transcriptome of M. dubia. (PDF 7038 kb)

Additional file 3: Table S2. Genic-SSR characteristics of M. dubia. (CSV $330 \mathrm{~kb}$ )

Additional file 4: Table S3. Primers characteristics for genic-SSR of M. dubia. (CSV 1694 kb)

Additional file 5: Table S4. SNPs in unigenes of M. dubia. (XLSX 2653 kb) Additional file 6: Table S5. Summary of SNPs effect in M. dubia. (CSV 576 bytes)

Additional file 7: Figure S2. Flow chart of methods used. (PNG 495 kb)

\section{Competing interests}

The authors declare that they have no competing interests.

\section{Authors' contributions}

JCC conceived the study, participated in the study design, obtained funds for the research, coordinated activities, and participated in the preparation of the manuscript. JDM, DR, MZ, and AB performed the bioinformatics analysis and participated in the preparation of the manuscript. MC participated in the study design, supervised samples preparation, and helped to draft the manuscript. LAC and AEM participated in botanical sample collection, in the isolation of total RNA and quality analysis for Illumina sequencing. SAl participated in the study design, supervised botanical samples collection, and helped to draft the manuscript. All authors read and approved the final manuscript.

\section{Acknowledgements}

This research was supported by grants from Universidad Nacional de la Amazonía Peruana. We also thank Dr. Jorge L. Marapara for his help with the infrastructure and equipment of Unidad Especializada de Biotecnología and Instituto Nacional de Innovación Agraria (INIA) - San Roque-lquitos for access to the germplasm collection of Myrciaria dubia. J. Dylan Maddox was supported by NSF International Fellowship OISE-1159178 during a portion of this research.

\section{Author details}

${ }^{1}$ Unidad Especializada de Biotecnología, Centro de Investigaciones de Recursos Naturales de la Amazonía (CIRNA), Universidad Nacional de la Amazonía Peruana (UNAP), Pasaje Los Paujiles S/N, San Juan Bautista, lquitos, Perú. ${ }^{2}$ Círculo de Investigación en Plantas con Efecto en Salud (FONDECYT N • 010-2014), Lima, Perú. ${ }^{3}$ Pritzker Laboratory for Molecular Systematics and Evolution, The Field Museum of Natural History, Chicago, IL, USA.

${ }^{4}$ Laboratorio de Biotecnología y Bioenergética, Universidad Científica del Perú (UCP), Av. Abelardo Quiñones km 2.5, San Juan Bautista, Iquitos, Perú. ${ }^{5}$ Laboratorio de Bioinformática y Biología Molecular, Laboratorios de Investigación y Desarrollo (LID), Facultad de Ciencias, Universidad Peruana Cayetano Heredia (UPCH), Av. Honorio Delgado 430, San Martín de Porres, Lima, Perú. ${ }^{6}$ FARVET S.A.C. Carretera Panamericana Sur Nº 766 Km 198.5, Chincha Alta, Ica, Perú. Department of Horticulture, Virginia Tech, Blacksburg, VA 24061, USA. ${ }^{8}$ Área de Conservación de Recursos Fitogenéticos, Instituto Nacional de Innovación Agraria (INIA), Calle San Roque 209, lquitos, Perú. 
Received: 11 December 2014 Accepted: 17 November 2015 Published online: 24 November 2015

\section{References}

1. Ribeiro da Costa I, Forni-Martins ER. Chromosome studies in species of Eugenia, Myrciaria and Plinia (Myrtaceae) from south-eastern Brazil. Aust J Bot. 2006;54(4):409-15.

2. Ueda H, Kuroiwa E, Tachibana Y, Kawanishi K, Ayala F, Moriyasu M. Aldose reductase inhibitors from the leaves of Myrciaria dubia (H. B. \& K.) McVaugh. Phytomedicine Int J Phytother Phytopharm. 2004;11(7-8):652-6.

3. Zanatta CF, Cuevas E, Bobbio FO, Winterhalter P, Mercadante AZ. Determination of anthocyanins from camu-camu (Myrciaria dubia) by HPLC-PDA, HPLC-MS, and NMR. J Agric Food Chem. 2005;53(24):9531-5.

4. Akachi T, Shiina Y, Kawaguchi T, Kawagishi H, Morita T, Sugiyama K. 1-methylmalate from camu-camu (Myrciaria dubia) suppressed D-galactosamine-induced liver injury in rats. Biosci Biotechnol Biochem. 2010;74(3):573-8

5. Fracassetti D, Costa C, Moulay L, Tomás-Barberán FA. Ellagic acid derivatives, ellagitannins, proanthocyanidins and other phenolics, vitamin $C$ and antioxidant capacity of two powder products from camu-camu fruit (Myrciaria dubia). Food Chem. 2013;139(1-4):578-88.

6. Inoue T, Komoda H, Uchida T, Node K. Tropical fruit camu-camu (Myrciaria dubia) has anti-oxidative and anti-inflammatory properties. J Cardiol. 2008;52(2):127-32.

7. Justi KC, Visentainer JV, de Souza N E, Matsushita M. Nutritional composition and vitamin C stability in stored camu-camu (Myrciaria dubia) pulp. Arch Latinoam Nutr. 2000;50(4):405-8.

8. Imán S, Bravo L, Sotero V, Oliva C. Contenido de vitamina C en frutos de camu camu Myrciaria dubia (H.B.K) Mc Vaugh, en cuatro estados de maduración, procedentes de la Colección de Germoplasma del INIA Loreto, Perú. Sci Agropecu. 2011;2(3):123-30.

9. Klimczak I, Małecka M, Szlachta M, Gliszczyńska-Świgło A. Effect of storage on the content of polyphenols, vitamin $\mathrm{C}$ and the antioxidant activity of orange juices. J Food Compos Anal. 2007;20(3-4):313-22.

10. Castro JC, Gutiérrez F, Acuña C, Cerdeira LA, Tapullima A, Marianela C, et al. Variación del contenido de vitamina C y antocianinas en Myrciaria dubia "camu-camu.". Rev Soc Quím Perú. 2013;79(4):319-30.

11. Wheeler $\mathrm{GL}$, Jones MA, Smirnoff $\mathrm{N}$. The biosynthetic pathway of vitamin C in higher plants. Nature. 1998:393(6683):365-9.

12. Valpuesta $V$, Botella MA. Biosynthesis of L-ascorbic acid in plants: new pathways for an old antioxidant. Trends Plant Sci. 2004;9(12):573-7.

13. Gallie DR. L-ascorbic acid: a multifunctional molecule supporting plant growth and development. Scientifica. 2013;2013:795964.

14. Li D, Deng Z, Qin B, Liu X, Men Z. De novo assembly and characterization of bark transcriptome using Illumina sequencing and development of EST-SSR markers in rubber tree (Hevea brasiliensis Muell. Arg.). BMC Genomics. 2012;13:192.

15. Ashrafi H, Hill T, Stoffel K, Kozik A, Yao J, Chin-Wo SR, et al. De novo assembly of the pepper transcriptome (Capsicum annuum): a benchmark for in silico discovery of SNPs. SSRs and candidate genes. BMC Genomics. 2012;13:571.

16. Natarajan P, Parani M. De novo assembly and transcriptome analysis of five major tissues of Jatropha curcas L. using GS FLX titanium platform of 454 pyrosequencing. BMC Genomics. 2011;12:191.

17. Li C, Wang Y, Huang X, Li J, Wang H, Li J. De novo assembly and characterization of fruit transcriptome in Litchi chinensis Sonn and analysis of differentially regulated genes in fruit in response to shading. BMC Genomics. 2013;14:552.

18. Guo X, Li Y, Li C, Luo H, Wang L, Qian J, et al. Analysis of the Dendrobium officinale transcriptome reveals putative alkaloid biosynthetic genes and genetic markers. Gene. 2013;527(1):131-8.

19. Ong WD, Voo L-YC, Kumar VS. De novo assembly, characterization and functional annotation of pineapple fruit transcriptome through massively parallel sequencing. PloS One. 2012;7(10), e46937.

20. Martínez-López LA, Ochoa-Alejo N, Martínez O. Dynamics of the chili pepper transcriptome during fruit development. BMC Genomics. 2014;15:143.

21. Wu H, Jia H, Ma X, Wang S, Yao Q, Xu W, et al. Transcriptome and proteomic analysis of mango (Mangifera indica Linn) fruits. J Proteomics. 2014;105:19-30.
22. Hyun TK, Rim Y, Jang H-J, Kim CH, Park J, Kumar R, et al. De novo transcriptome sequencing of Momordica cochinchinensis to identify genes involved in the carotenoid biosynthesis. Plant Mol Biol. 2012;79(4-5):413-27.

23. Xie M, Huang $Y$, Zhang $Y$, Wang $X$, Yang H, Yu O, et al. Transcriptome profiling of fruit development and maturation in Chinese white pear (Pyrus bretschneideri Rehd). BMC Genomics. 2013;14:823.

24. Li X, Sun H, Pei J, Dong Y, Wang F, Chen H, et al. De novo sequencing and comparative analysis of the blueberry transcriptome to discover putative genes related to antioxidants. Gene. 2012;511(1):54-61.

25. Que Y, Su Y, Guo J, Wu Q, Xu L. A global view of transcriptome dynamics during Sporisorium scitamineum challenge in sugarcane by RNA-seq. PloS One. 2014;9(8), e106476.

26. Wang Z, Hu H, Goertzen LR, McElroy JS, Dane F. Analysis of the Citrullus colocynthis transcriptome during water deficit stress. PloS One. 2014;9(8), e104657.

27. Lai Z, Lin Y. Analysis of the global transcriptome of longan (Dimocarpus longan Lour.) embryogenic callus using Illumina paired-end sequencing. BMC Genomics. 2013;14:561.

28. Wei W, Qi X, Wang L, Zhang Y, Hua W, Li D, et al. Characterization of the sesame (Sesamum indicum L.) global transcriptome using Illumina pairedend sequencing and development of EST-SSR markers. BMC Genomics. 2011;12:451.

29. Liu J, Mei D, Li Y, Huang S, Hu Q. Deep RNA-Seq to unlock the gene bank of floral development in Sinapis arvensis. PloS One. 2014;9(9), e105775.

30. Shi C-Y, Yang H, Wei C-L, Yu O, Zhang Z-Z, Jiang C-J, et al. Deep sequencing of the Camellia sinensis transcriptome revealed candidate genes for major metabolic pathways of tea-specific compounds. BMC Genomics. 2011;12:131.

31. Ge X, Chen H, Wang H, Shi A, Liu K. De novo assembly and annotation of Salvia splendens transcriptome using the Illumina platform. PloS One. 2014;9(3), e87693.

32. Wang Z, Fang B, Chen J, Zhang X, Luo Z, Huang L, et al. De novo assembly and characterization of root transcriptome using Illumina paired-end sequencing and development of cSSR markers in sweet potato (Ipomoea batatas). BMC Genomics. 2010;11:726.

33. Liu X, Lu Y, Yuan Y, Liu S, Guan C, Chen S, et al. De novo transcriptome of Brassica juncea seed coat and identification of genes for the biosynthesis of flavonoids. PloS One. 2013;8(8), e71110.

34. Li H, Dong Y, Yang J, Liu X, Wang Y, Yao N, et al. De novo transcriptome of safflower and the identification of putative genes for oleosin and the biosynthesis of flavonoids. PloS One. 2012;7(2), e30987.

35. Wang S, Wang X, He Q, Liu X, Xu W, Li L, et al. Transcriptome analysis of the roots at early and late seedling stages using Illumina paired-end sequencing and development of EST-SSR markers in radish. Plant Cell Rep. 2012;31(8):1437-47.

36. Zerbino DR, Birney E. Velvet: algorithms for de novo short read assembly using de Bruijn graphs. Genome Res. 2008;18(5):821-9.

37. Schulz MH, Zerbino DR, Vingron M, Birney E. Oases: robust de novo RNAseq assembly across the dynamic range of expression levels. Bioinformatics. 2012;28(8):1086-92.

38. Grabherr MG, Haas BJ, Yassour M, Levin JZ, Thompson DA, Amit I, et al. Trinity: reconstructing a full-length transcriptome without a genome from RNA-Seq data. Nat Biotechnol. 2011;29(7):644-52.

39. Huang X, Madan A. CAP3: A DNA sequence assembly program. Genome Res. 1999;9(9):868-77.

40. Hanson AD, Pribat A, Waller JC, de Crécy-Lagard V. 'Unknown' proteins and 'orphan' enzymes: the missing half of the engineering parts list - and how to find it. Biochem J. 2010:425(1):1-11.

41. Sorokina M, Stam M, Médigue C, Lespinet O, Vallenet D. Profiling the orphan enzymes. Biol Direct. 2014;9:10.

42. Schnoes AM, Brown SD, Dodevski I, Babbitt PC. Annotation error in public databases: misannotation of molecular function in enzyme superfamilies. PLoS Comput Biol. 2009;5(12), e1000605.

43. De Crécy-Lagard V. Variations in metabolic pathways create challenges for automated metabolic reconstructions: examples from the tetrahydrofolate synthesis pathway. Comput Struct Biotechnol J. 2014;10(16):41-50.

44. Zhao S, Kumar R, Sakai A, Vetting MW, Wood BM, Brown S, et al. Discovery of new enzymes and metabolic pathways by using structure and genome context. Nature. 2013;502(7473):698-702.

45. Kumar R, Zhao S, Vetting MW, Wood BM, Sakai A, Cho K, et al. Prediction and biochemical demonstration of a Catabolic pathway for the osmoprotectant proline betaine. MBio. 2014;5(1):e00933-13. 
46. Bradbury LMT, Niehaus TD, Hanson AD. Comparative genomics approaches to understanding and manipulating plant metabolism. Curr Opin Biotechnol. 2013;24(2):278-84.

47. Smirnoff N, Wheeler GL. Ascorbic acid in plants: biosynthesis and function. Crit Rev Biochem Mol Biol. 2000;35(4):291-314.

48. Lorence A, Chevone BI, Mendes P, Nessler CL. myo-inositol oxygenase offers a possible entry point into plant ascorbate biosynthesis. Plant Physiol. 2004; 134(3):1200-5.

49. Wolucka BA, Van Montagu M. GDP-mannose 3',5'-epimerase forms GDP-Lgulose, a putative intermediate for the de novo biosynthesis of vitamin $\mathrm{C}$ in plants. J Biol Chem. 2003;278(48):47483-90.

50. Xu Q, Chen L-L, Ruan X, Chen D, Zhu A, Chen C, et al. The draft genome of sweet orange (Citrus sinensis). Nat Genet. 2013;45(1):59-66.

51. Crowhurst RN, Gleave AP, MacRae EA, Ampomah-Dwamena C, Atkinson RG, Beuning $L L$, et al. Analysis of expressed sequence tags from Actinidia: applications of a cross species EST database for gene discovery in the areas of flavor, health, color and ripening. BMC Genomics. 2008;9:351.

52. Li $Y, X u$ C, Lin X, Cui B, Wu R, Pang $X$. De novo assembly and characterization of the fruit transcriptome of Chinese Jujube (Ziziphus jujuba Mill.) Using 454 pyrosequencing and the development of novel trinucleotide SSR markers. PLoS One. 2014;9(9):e106438.

53. Feng C, Chen M, Xu C, Bai L, Yin X, Li X, et al. Transcriptomic analysis of Chinese bayberry (Myrica rubra) fruit development and ripening using RNA-Seq. BMC Genomics. 2012;13:19.

54. Foyer C, Graham N. Ascorbate and glutathione: the heart of the Redox Hub. Plant Physiol. 2011;155(1):2-18.

55. Gest N, Gautier H, Stevens R. Ascorbate as seen through plant evolution: the rise of a successful molecule? J Exp Bot. 2013;64(1):33-53.

56. Tapullima A. Biochemical characterization of L-galactono/L-gulono-1,4lactone dehydrogenase from Myrciaria dubia (Kunth) McVaugh "camu camu. ". Theses Bachelor of Pharmaceutical Chemistry: Universidad Nacional de la Amazonía Peruana; 2013

57. Babtie A, Tokuriki N, Hollfelder F. What makes an enzyme promiscuous? Curr Opin Chem Biol. 2010;14(2):200-7.

58. Linster CL, Gomez TA, Christensen KC, Adler LN, Young BD, Brenner C, et al. Arabidopsis VTC2 encodes a GDP-L-galactose phosphorylase, the last unknown enzyme in the Smirnoff-Wheeler pathway to ascorbic acid in plants. J Biol Chem. 2007;282(26):18879-85.

59. Mieda T, Yabuta Y, Rapolu M, Motoki T, Takeda T, Yoshimura K, et al. Feedback inhibition of spinach I-galactose dehydrogenase by l-ascorbate. Plant Cell Physiol. 2004;45(9):1271-9.

60. Palma JM, Jiménez A, Sandalio LM, Corpas FJ, Lundqvist M, Gómez M, et al. Antioxidative enzymes from chloroplasts, mitochondria, and peroxisomes during leaf senescence of nodulated pea plants. J Exp Bot. 2006:57(8):1747-58.

61. Locato V, de Pinto MC, De Gara L. Different involvement of the mitochondrial, plastidial and cytosolic ascorbate-glutathione redox enzymes in heat shock responses. Physiol Plant. 2009;135(3):296-306.

62. Noctor G, Arisi A-CM, Jouanin L, Kunert KJ, Rennenberg H, Foyer CH. Glutathione: biosynthesis, metabolism and relationship to stress tolerance explored in transformed plants. J Exp Bot. 1998:49(321):623-47.

63. Kruger NJ, von Schaewen A. The oxidative pentose phosphate pathway: structure and organisation. Curr Opin Plant Biol. 2003;6(3):236-46.

64. Drincovich MF, Casati P, Andreo CS. NADP-malic enzyme from plants: a ubiquitous enzyme involved in different metabolic pathways. FEBS Lett. 2001;490(1-2):1-6.

65. Kramer DM, Avenson TJ, Edwards GE. Dynamic flexibility in the light reactions of photosynthesis governed by both electron and proton transfer reactions. Trends Plant Sci. 2004;9(7):349-57.

66. Varshney RK, Graner A, Sorrells ME. Genic microsatellite markers in plants: features and applications. Trends Biotechnol. 2005;23(1):48-55.

67. Rojas S, Rodrigues D, Lima M, Fhilo S. Desenvolvimento e mapeamento de microssatélites gênicos (EST-SSRs) de camu-camu (Myrciaria dubia [H.B.K.] McVaug. Rev Corpoica. 2008;9(1):1421.

68. Rojas S, Yuyama K, Clement C, Ossamu E. Diversidade genética em acessos do banco de germoplasma de camu-camu (Myrciaria dubia [H.B.K.] McVaugh) do INPA usando marcadores microssatélites (EST-SSR). Rev Corpoica. 2011;12(1):51-64

69. Dutta S, Kumawat G, Singh BP, Gupta DK, Singh S, Dogra V, et al. Development of genic-SSR markers by deep transcriptome sequencing in pigeonpea [Cajanus cajan (L.) Millspaugh]. BMC Plant Biol. 2011;11:17.
70. Fu N, Wang Q, Shen H-L. De novo assembly, gene annotation and marker development using Illumina paired-end transcriptome sequences in celery (Apium graveolens L.). PloS One. 2013;8(2):e57686.

71. Zhao Y, Williams R, Prakash CS, He G. Identification and characterization of gene-based SSR markers in date palm (Phoenix dactylifera L.). BMC Plant Biol. 2012;12:237.

72. Kantety RV, La Rota M, Matthews DE, Sorrells ME. Data mining for simple sequence repeats in expressed sequence tags from barley, maize, rice, sorghum and wheat. Plant Mol Biol. 2002;48(5-6):501-10.

73. Varshney RK, Thiel $\mathrm{T}$, Stein N, Langridge $\mathrm{P}$, Graner A. In silico analysis on frequency and distribution of microsatellites in ESTs of some cereal species. Cell Mol Biol Lett. 2002;7(2A):537-46.

74. Ting N-C, Zaki NM, Rosli R, Low E-TL, Ithnin M, Cheah S-C, et al. SSR mining in oil palm EST database: application in oil palm germplasm diversity studies. J Genet. 2010;89(2):135-45.

75. Li Y-C, Korol AB, Fahima T, Nevo E. Microsatellites within genes: structure, function, and evolution. Mol Biol Evol. 2004;21(6):991-1007.

76. Katti MV, Ranjekar PK, Gupta VS. Differential distribution of simple sequence repeats in eukaryotic genome sequences. Mol Biol Evol. 2001;18(7):1161-7.

77. Morgante M, Hanafey M, Powell W. Microsatellites are preferentially associated with nonrepetitive DNA in plant genomes. Nat Genet 2002;30(2):194-200.

78. Fujimori S, Washio T, Higo K, Ohtomo Y, Murakami K, Matsubara K, et al. A novel feature of microsatellites in plants: a distribution gradient along the direction of transcription. FEBS Lett. 2003;554(1-2):17-22.

79. Zhang L, Yuan D, Yu S, Li Z, Cao Y, Miao Z, et al. Preference of simple sequence repeats in coding and non-coding regions of Arabidopsis thaliana. Bioinformatics. 2004;20(7):1081-6.

80. Grover A, Aishwarya V, Sharma PC. Biased distribution of microsatellite motifs in the rice genome. Mol Genet Genomics. 2007;277(5):469-80.

81. Zhao Z, Guo C, Sutharzan S, Li P, Echt CS, Zhang J, et al. Genome-wide analysis of tandem repeats in plants and green algae. G3 (Bethesda). 2014;4(1):67-78

82. Huang S, Deng L, Guan M, Li J, Lu K, Wang H, et al. Identification of genome-wide single nucleotide polymorphisms in allopolyploid crop Brassica napus. BMC Genomics. 2013;14:717.

83. Dalton-Morgan J, Hayward A, Alamery S, Tollenaere R, Mason AS, Campbell E, et al. A high-throughput SNP array in the amphidiploid species Brassica napus shows diversity in resistance genes. Funct Integr Genomics. 2014;14(4):643-55

84. Pootakham W, Shearman JR, Ruang-Areerate P, Sonthirod C, Sangsrakru D, Jomchai N, et al. Large-scale SNP discovery through RNA sequencing and SNP genotyping by targeted enrichment sequencing in Cassava (Manihot esculenta Crantz). PloS One. 2014;9(12), e116028.

85. Wei L, Miao H, Li C, Duan Y, Niu J, Zhang T, et al. Development of SNP and InDel markers via de novo transcriptome assembly in Sesamum indicum L. Mol Breed. 2014:34(4):2205-17.

86. Salgado LR, Koop DM, Pinheiro DG, Rivallan R, Le Guen V, Nicolás MF, et al. De novo transcriptome analysis of Hevea brasiliensis tissues by RNA-seq and screening for molecular markers. BMC Genomics. 2014;15:236.

87. Ersoz ES, Wright MH, Pangilinan JL, Sheehan MJ, Tobias C, Casler MD, et al. SNP discovery with EST and NextGen sequencing in switchgrass (Panicum virgatum L.). PloS One. 2012;7(9):e44112.

88. Wolfe KH, Li WH, Sharp PM. Rates of nucleotide substitution vary greatly among plant mitochondrial, chloroplast, and nuclear DNAs. Proc Natl Acad Sci U S A. 1987:84(24):9054-8.

89. Ehrlich M, Zhang X-Y, Inamdar NM. Spontaneous deamination of cytosine and 5-methylcytosine residues in DNA and replacement of 5methylcytosine residues with cytosine residues. Mutat Res Genet Toxicol. 1990;238(3):277-86.

90. Mammadov J, Aggarwal R, Buyyarapu R, Kumpatla S. SNP markers and their impact on plant breeding. Int J Plant Genomics. 2012;2012:728398.

91. Gómez JCC, Reátegui ADCE, Flores JT, Saavedra RR, Ruiz MC, Correa SAI. Isolation of high-quality total RNA from leaves of Myrciaria dubia "camu camu.". Prep Biochem Biotechnol. 2013;43(6):527-38.

92. Sambrook J, Fritsch EF, Maniatis T. Molecular cloning: a laboratory manual. Second: Cold Spring Harbor Laboratory Press; 1989.

93. Bolger AM, Lohse M, Usadel B. Trimmomatic: a flexible trimmer for Illumina sequence data. Bioinformatics. 2014;30(15):2114-20.

94. Melicher D, Torson AS, Dworkin I, Bowsher JH. A pipeline for the de novo assembly of the Themira biloba (Sepsidae: Diptera) transcriptome using a multiple k-mer length approach. BMC Genomics. 2014;15:188. 
95. Chen T-W, Gan R-CR, Wu TH, Huang P-J, Lee C-Y, Chen Y-YM, et al. FastAnnotator-an efficient transcript annotation web tool. BMC Genomics. 2012;13 Suppl 7

96. Conesa A, Götz S, García-Gómez JM, Terol J, Talón M, Robles M. Blast2GO: a universal tool for annotation, visualization and analysis in functional genomics research. Bioinformatics. 2005;21(18):3674-6.

97. Claudel-Renard C, Chevalet C, Faraut T, Kahn D. Enzyme-specific profiles for genome annotation: PRIAM. Nucleic Acids Res. 2003;31(22):6633-9.

98. Marchler-Bauer A, Zheng C, Chitsaz F, Derbyshire MK, Geer LY, Geer RC, et al. CDD: conserved domains and protein three-dimensional structure. Nucleic Acids Res. 2013:41(Database issue):D348-52.

99. Kanehisa M, Goto S. KEGG: kyoto encyclopedia of genes and genomes. Nucleic Acids Res. 2000;28(1):27-30

100. Moriya Y, Itoh M, Okuda S, Yoshizawa AC, Kanehisa M. KAAS: an automatic genome annotation and pathway reconstruction server. Nucleic Acids Res. 2007;35(Web Server issue):W182-5.

101. Faircloth BC. msatcommander: detection of microsatellite repeat arrays and automated, locus-specific primer design. Mol Ecol Resour. 2008;8(1):92-4.

102. Rozen S, Skaletsky H. Primer3 on the WWW for general users and for biologist programmers. Methods Mol Biol. 2000;132:365-86.

103. Li H, Durbin R. Fast and accurate short read alignment with Burrows-Wheeler transform. Bioinformatics. 2009:25(14):1754-60.

104. Li H, Handsaker B, Wysoker A, Fennell T, Ruan J, Homer N, et al. 1000 genome project data processing subgroup: the sequence alignment/map format and SAMtools. Bioinformatics. 2009;25(16):2078-9.

105. Cingolani $P$, Platts $A$, Wang $L L$, Coon M, Nguyen $T$, Wang $L$, et al. A program for annotating and predicting the effects of single nucleotide polymorphisms, SnpEff: SNPs in the genome of Drosophila melanogaster strain w1118; iso-2; iso-3. Fly (Austin). 2012;6(2):80-92.

\section{Submit your next manuscript to BioMed Central and we will help you at every step:}

- We accept pre-submission inquiries

- Our selector tool helps you to find the most relevant journal

- We provide round the clock customer support

- Convenient online submission

- Thorough peer review

- Inclusion in PubMed and all major indexing services

- Maximum visibility for your research 